\title{
Nanobiocatalyst beds with Fenton process for removal of methylene blue
}

\author{
Azize Alayli ${ }^{1,2}$ (D) Hayrunnisa Nadaroglu ${ }^{2,3} \cdot$ Esra Turgut $^{2}$
}

Received: 4 April 2020 / Accepted: 13 January 2021 / Published online: 27 January 2021

(c) The Author(s) 2021

\begin{abstract}
The remediation of methylene blue from wastewater using chitosan-sunflower-nano-iron (CSN) beds was examined in this study with the Fenton process. Nano-iron is synthesized using the green synthesis process. Then, biopolymer beds obtained nano-iron, sunflower tray waste, and chitosan. These beds used the Fenton process for removing Methylene blue (MB) from water. Beds synthesis and dye removing are characterized using SEM, TEM, FTIR, and XRD techniques. For the method optimization, the effects of dye concentration, temperature, $\mathrm{pH}, \mathrm{H}_{2} \mathrm{O}_{2}$, and amount of biocatalyst were studied. The result of the wavelength scan was found $660 \mathrm{~nm}$ for methylene blue dye. Using CSN, catalyst was very effective in color removal for MB under optimal conditions. The highest removal rate $98 \%$ was obtained at $\mathrm{pH} 6$ for $270 \mathrm{~min}$. The optimum conditions for the MB dye are as follows; dye concentration: $25 \mathrm{mg} / \mathrm{L}$, amount of absorbent: $2.5 \mathrm{mg} / \mathrm{mL}$, temperature: $60{ }^{\circ} \mathrm{C}, \mathrm{H}_{2} \mathrm{O}_{2}$ amount: $20 \mathrm{mg} / \mathrm{L}(600 \mu \mathrm{L}, 30 \%)$. When the experiment is studied in optimum conditions, max. dye removal was calculated to be $98 \%$. From SEM, TEM, XRD, and FTIR results, the change in the surface of the biocatalyst could be clearly observed. It is understood that the biocatalyst synthesized from the results we obtained easily removed a large amount of dye (MB).
\end{abstract}

Keywords Fenton processes $\cdot$ Methylene blue $\cdot$ Nanobiocatalyst $\cdot$ Wastewater $\cdot$ Sunflower waste

\section{Introduction}

One of the most emphasized issues in global environments is water pollution caused by microorganisms, inorganic, organic, and some other chemicals (Maldonado et al. 2017). Although most of the world is made up of water, water is a scarce resource in many parts of the world due to the limited water consumption and drinking. Therefore, conservation of water resources is an important issue (Marin 2007). The

Azize Alayli

aalayli@subu.edu.tr

Hayrunnisa Nadaroglu

hnisa25@atauni.edu.tr

Esra Turgut

esraturgut034@gmail.com

1 Nursing Department, Faculty of Health Sciences, Sakarya University of Applied Sciences, Akyazı, Sakarya, Turkey

2 Department of Nano-Science and Nano-Engineering, Faculty of Engineering, Ataturk University, 25240 Erzurum, Turkey

3 Department of Food Technology, Vocational College of Technical Sciences, Ataturk University, 25240 Erzurum, Turkey production and use of chemicals in different fields increase exponentially with each passing day. Then, people discharge these chemicals to water sources in different ways (Ameta 2013). Many of these chemicals have chain effects on the environment. Due to the structural properties of the chemicals that mix into the waters, it has been determined by researches that they exhibit carcinogenic, mutagenic, and toxic, and teratogenic properties. The dyestuffs used in many industries also exhibit the properties described when mixed with water (Houas et al. 2001; Karadağ et al. 2006). Methylene blue (MB) is a heteropolyaromatic dye widely used for cotton printing in the textile field. In addition to its use for dyeing textile, tannins, and leather, its presence in the chemical industry and medical applications is found in the literature. In addition, it is preferred as a model paint in paint removal studies (Loloei and Rezaee 2016). Removal works of wastes in waters are very important for both removing industrial wastes and protecting the environment. The most commonly used methods in water treatment today are reverse osmosis, ion exchange technology, precipitation, adsorption, biodegradation, and chemical methods. In addition, some of the other methods used for water pollutants are photochemistry, radiolysis, sonolysis, and Fenton methods. 
These methods are preferred for the removal of compounds that are difficult to remove from water. Advanced oxidation processes involving the Fenton process have a very important place among these techniques (Gupta et al. 2004). The Fenton process is used for this process to decompose radically dangerous organic compounds Horstman Fenton ve Jackson (1899). In the Fenton process, hydrogen peroxide and iron used to form the reagent. Generally, the Fenton reaction takes place more efficiently in an acidic environment (Ai et al. 2007). Fenton reaction contains hydrogen peroxide and $\mathrm{Fe}^{2+}$, while Fenton-like reactions include combinations of hydrogen peroxide and $\mathrm{Fe}^{3+}, \mathrm{Fe}^{2+} / \mathrm{Fe}^{3+}$ or $\mathrm{Cu}^{2+}$. In addition, $\mathrm{FeO}, \mathrm{Fe}_{3} \mathrm{O}_{4}$ (magnetite), and $\mathrm{Fe}_{2} \mathrm{O}_{3}$ (maghemite) have been named as agents used in Fenton and Fenton-like reactions (Ai et al. 2017).

Chitosan-based absorbents have attracted considerable attention on the absorption of paints. Chitosan is one of the world's most abundant and low-cost biopolymers with a variety of properties as an ideal absorbent for removing pollutants from wastewater. The chitin is treated in potassium hydroxide to produce a product called dissolvable chitosan (). Sunflowers (Helianthus annuus L.) grow in dry areas, so they have reported being heavily affected by environmental conditions. After the hybrids entered production in the 1980s, the sunflower yield increased greatly. In addition to growing sunflower plants as the basic product every year, sunflower growers face their waste in the province. Even if sunflower waste is not very common, it is used as fuel, paper production, and animal feed. However, this amount is very low, usually, after harvesting, sunflower wastes are left in the field, plowed, or burned (Kaya 2016).

Although it has been understood that dyes can be removed from water by many different methods described so far, it has been revealed that these methods have different disadvantages. One of these disadvantages is that the Fenton reagent used cannot be easily removed from the water environment. In the planned study, environmentally friendly approaches will be followed, and firstly, nano-iron particles will be synthesized with the green synthesis method in order to be used as Fenton reagent.

Then, chitosan and sunflower wastes will be used so that the synthesized nanoparticles do not interfere with the water environment and cause contamination and in order to reuse. In this way, the Fenton reagent will be prevented from passing into the solvent environment and it is thought that the reactive high degradation products resulting from the Fenton reaction can be absorbed on chitosan and sunflower wastes without passing into the water and removed from the environment. By using waste sunflowers that are lower in terms of cost, the production cost of the nanobiosorbent will be reduced and a nanobiocatalyst that can be used effectively will be obtained. Therefore, in our research, the sunflower waste in the tray was dried and ground, and then chitosan sunflower biosorbent beads with a large surface were obtained using chitosan. Afterward, the magnetic iron nanoparticles synthesized by the green synthesis method were attached to the structure and these bionanocatalysts were used for the active removal of methylene blue dye from the waters with the help of Fenton process with the catalytic effect.

\section{Experimental section}

\section{Reagents}

Chemicals used in the study are chitosan (Sigma-Aldrich $75 \%$ purity), acetic acid $\left(\mathrm{CH}_{3} \mathrm{COOH}\right.$ Sigma-Aldrich $\left.100 \%\right)$, sodium hydroxide ( $\mathrm{NaOH}$ Merck $99-100 \%)$, hydrochloric acid (Merck-HCl 37\%), hydrogen peroxide $\left(\mathrm{H}_{2} \mathrm{O}_{2} 30 \%\right)$. Dye solutions at the experimental stage are Methylene blue (Merck 40\%) dyes. Iron (III) chloride solution $\left(\mathrm{FeCl}_{3}\right.$ Sigma-Aldrich $97 \%)$ was used as sodium phosphate $\left(\mathrm{Na}_{3} \mathrm{PO}_{4}\right.$ Merck $\geq 99 \%$ ).

\section{Synthesis of iron nanoparticles}

Production of nanoparticles has been done with $1 \mathrm{mM}$ $\mathrm{FeCl}_{3}$ solution and fig (Ficus carica) plant using green synthesis method. The reduction in iron ions was used to extract fresh fig plants. After washing $100 \mathrm{~g}$ of green fig plant with distilled water to remove dust and waste on it, the blender device was disintegrated with $250 \mathrm{~mL}$ distilled water. Then, the extract filtered with the help of filter paper was used for the synthesis of iron nanoparticles by green synthesis method. In $100 \mathrm{~mL}$ of $1 \mathrm{mM} \mathrm{FeCl}_{3}$ solution, $10 \mathrm{~mL}$ of fig extract was added as green synthesis reduction reagent and NP synthesis reaction was monitored spectrophotometrically. Characterization of iron nanoparticles and nanocatalyst synthesized under optimum conditions: Uvspectrophotometer, XRD, FT-IR, SEM, and TEM analyses were used (Turgut 2019; Gungor et al. 2015; Karaduman et al. 2017; Nalci 2018).

\section{Preparation of nanobiosorbents}

The sunflowers were collected from the field of Erzurum city in September 2019. The tray part was washed and then dried in daylight. The dried sunflowers were pulverized with the help of a blender. Powdered sunflower was used for chitosan sunflower beds. 1:1(w/w) chitosan, and sunflower tray powder was polymerized in 5\% acetic acid. The polymerized mixture was dropped by means of a syringe into $1 \mathrm{~L}$ of $2 \mathrm{M}$ sodium hydroxide $(\mathrm{NaOH})$ solution to form beads. The beads were washed three times with distilled water. Becoming 1:0.05 (w/w), chitosan sunflower beads and iron 
nanoparticles were added to the reaction mixture and stirred at $400 \mathrm{rpm}$ for $3 \mathrm{~h}$. The beads filtered from the solution were washed three times with distilled water and stayed to dry for $48 \mathrm{~h}$. in an oven at $40{ }^{\circ} \mathrm{C}$ (Gungor et al. 2014, Nadaroglu et al. 2015) (Fig. 1).

\section{Determination of optimum conditions for dyestuff removal by Fenton reaction}

In order to determine the most suitable conditions for the removal of dyes by Fenton reaction, stages of temperature, $\mathrm{pH}$, nanobiocatalyst amount, dyestuff concentration, and hydrogen peroxide $\left(\mathrm{H}_{2} \mathrm{O}_{2}\right)$ concentration were examined separately and optimum conditions were determined(Gungor et al. 2016; Nadaroğlu 2018).

\section{Characterization techniques}

X-ray powder Diffraction patterns (XRD) were collected using a Panalytical Empyrean model. Fourier Transform Infrared (FT-IR) analysis was made using a Bruker Vertex 70 model. Transmission Electron Microscopy (TEM) images were recorded on a Hitachi Ht 7700 model. Scanning Electron Microscope (Zeiss Sigma 300 model) technique was used determination of the surface character of the material. The degradation of MB was studied by using UV-vis absorption (Beckman Coulter Du 730 model) (Loloei and Rezaee 2016).

\section{Results and discussion}

\section{Wavelength scanning with dyes for spectrophotometer}

Wavelength scanning was done using Beckman Coulter UV-VIS spectrophotometer by adding dyestuff into the quartz cuvette. The wavelength value, which gave the greatest peak in the wavelength scan for MB, was determined as $660 \mathrm{~nm}$. The most suitable wavelength was determined for dyestuffs, and this wavelength was used in optimization studies. Similar to our study, Abhilasha et al. found the OD of the dye as $660 \mathrm{~nm}$ in the method proposed for photo-catalytically removing methylene blue dye. Uddin et al. used $664 \mathrm{~nm}$ in their study (Uddin et al. 2009; Abhilasha 2016).

\section{Method optimization for dye removal by Fenton reaction}

\section{Determination of optimum reaction time}

For dye removal, samples were taken from the mixture at certain time intervals between 5-300 min to determine the optimum reaction time. Fenton reaction was established using the dyestuff MB $(25 \mathrm{mg} / \mathrm{L})$ and CSN $(2.5 \mathrm{mg} / \mathrm{L})+$ hydrogen peroxide $\left(\mathrm{CSN}+\mathrm{H}_{2} \mathrm{O}_{2}\right)$ nanobiocatalyst, and the best removal time was investigated (Fig. 2a). As seen in Fig. 2a, the best reaction was determined to be in the 270th min. Uddin et al. found it as $6 \mathrm{~h}$. (Uddin et al. 2009). Ayodamope in his study stated that the removal of the MB was 30 min (Ayodamope 2015).

\section{Optimum temperature study}

Using CSN, the effect of MB on removal by Fenton reaction was examined by performing 3 replications at 10 different temperatures $\left(5-80^{\circ} \mathrm{C}\right)$. The most suitable temperature for the removal of methylene blue using CSN was found to be $60{ }^{\circ} \mathrm{C}$ in our study (Fig. 2b). On the other hand, Ghosh and Bhattacharyya found the reaction temperature as $28{ }^{\circ} \mathrm{C}$ in their study for the removal of MB dye using Kaolinite (Ghosh and Bhattacharyya 2002). In another study, the absorption technique was used to remove MB dye from wastewater and the optimum remediation temperature was determined as $27 \pm 2$ degrees. In the work of Ayodamope;
Fig. 1 Synthesis of nanobiocatalyst

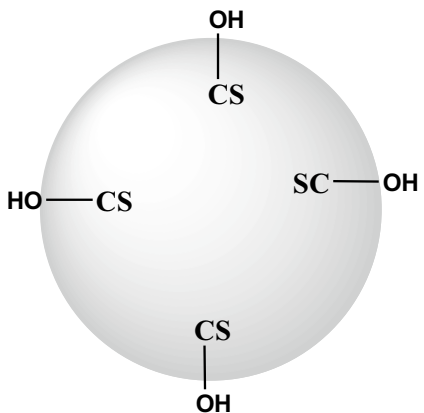

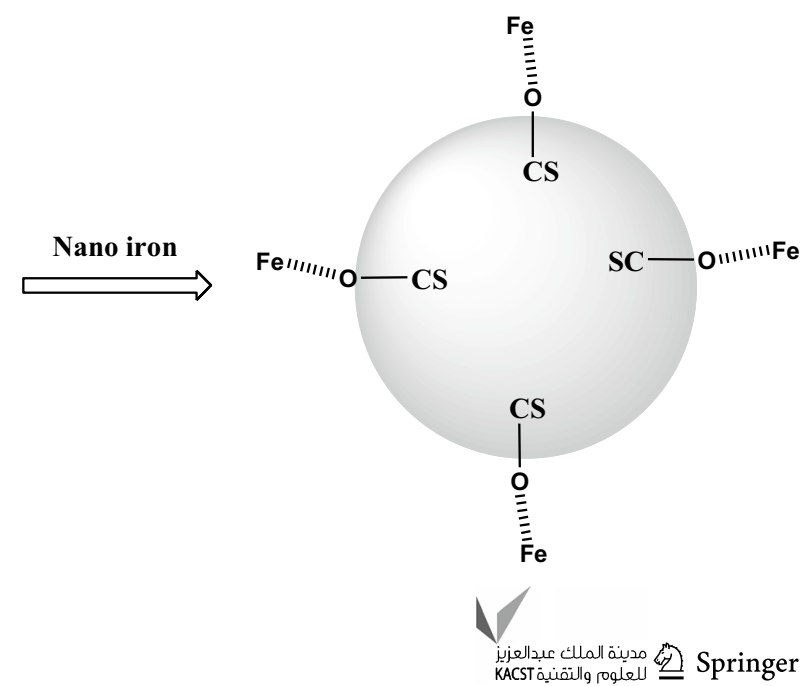


Fig. 2 a Effect of MB dye on Fenton reaction depending on time $\mathbf{b}$ determining the effect of the temperature on Fenton reaction $\mathbf{c}$ determining the effects on CSN amount and Fenton reaction rate $\mathbf{d}$ interaction of $\mathrm{MB}$ concentration with a fixed amount of CSN effect of $\mathrm{pH}$ on Fenton reaction rate $\mathbf{f}$ effect of $\mathrm{H}_{2} \mathrm{O}_{2}$ amount in the removal of MB substance with Fenton reaction
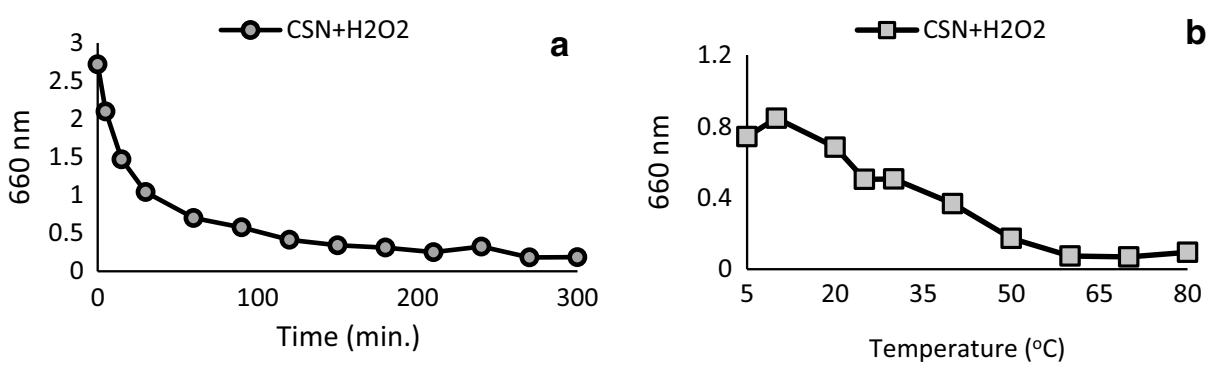

b
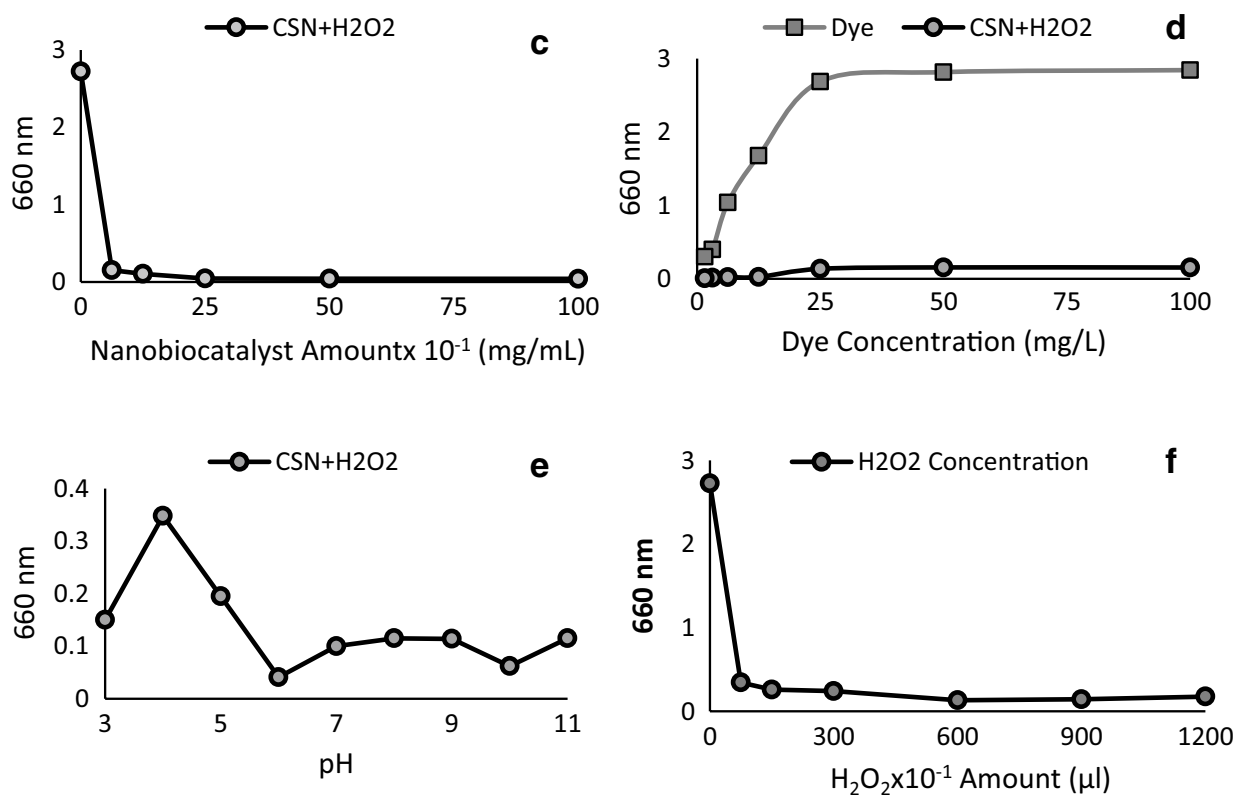

it has been shown that $\mathrm{MB}$ dye is best removed from wastewater at temperatures between $30^{\circ} \mathrm{C}$ and $45^{\circ} \mathrm{C}$ (Uddin et al. 2009; Ayodamope 2015).

\section{Determination optimum nanobiocatalyst amount}

To measure how the reaction rate varies with the amount of nano-biocatalyst, a range of 0.625-10 mg CSN were examined. The different amounts of nanobiocatalyst weighed in the analytical balance were added to $10 \mathrm{~mL}$ of $\mathrm{MB}$ solutions at a concentration of $25 \mathrm{~m} / \mathrm{L}$ and then mixed in the magnetic stirrer during the optimum contact time. Then, after centrifuging at $6000 \mathrm{xg}$ for $5 \mathrm{~min}$, the amount of MB dye was determined spectrophotometrically from the liquid part (Fig. 2c). The effect of CSN amount was examined in the range of $0.625-10 \mathrm{mg}$ bio-nanocatalyst agent. The amount of catalyst to remove MB was determined to be $2.50 \mathrm{mg} /$ $\mathrm{mL}$. In another research; biosorbent material was used and they found that the most appropriate amount of biosorbent was $0.8 \mathrm{~g} / \mathrm{L}$ (Ghosh and Bhattacharyya 2002). In a different study, iron was used as a Fenton catalyst and the optimal dosage was reported to be $1 \mathrm{mg} / \mathrm{L}$ (Ayodamope 2015).

\section{Optimum MB dye concentration}

In order to determine the optimum MB concentration removed, 3 replicates were studied. The experimental study was carried out by adding $2.5 \mathrm{mg} / \mathrm{mL}$ catalyst to $10 \mathrm{~mL} \mathrm{MB}$ solutions at a concentration of $1.56-100 \mathrm{mg} / \mathrm{L}$. The dye concentration with the most appropriate removal was determined as $25 \mathrm{mg} / \mathrm{L}$. (Fig. 2d). Abhilasha et al., using photo Fenton reaction, removed MB dye under the light. In their research, they determined that $2.33 \times 10^{-5} \mathrm{M}$ dyestuff was the optimum paint removal amount (Abhilasha 2016).

\section{Determination of optimal pH}

In our research, in order to investigate the effect of $\mathrm{pH}$ on the removal of dyes by Fenton reaction, reactions in the $\mathrm{pH}$ 2-10 range were carried out. Dyes were determined by the spectroscopic method in the liquid phase (Fig. 2e). From the findings, it was determined that the highest removal of $\mathrm{MB}$ dye from wastewater was realized by using CSN at $\mathrm{pH}$ 5.0.

Uddin et al. correlated the optimum $\mathrm{pH}$ range of 5-10 for methylene blue dye in biosorption on tea wastes. In their 
study, Abhilasha et al. showed that the optimum $\mathrm{pH}$ for the removal of MB dye from wastewater is 3.0. Because of his study, Ayodamope determined that the most suitable $\mathrm{pH}$ is in the range of 2-4 (Uddin et al. 2009). The findings we obtained in our studies are consistent with the results of the studies in the literature.

\section{Determination of optimum peroxide concentration}

The effect of $\mathrm{H}_{2} \mathrm{O}_{2}$ on the removal of $\mathrm{MB}$ dye, the experimental setup was established by adding $\mathrm{H}_{2} \mathrm{O}_{2}$ in the Fenton reaction medium in the range of $75-1200 \mu \mathrm{L}(30 \%)$. At the end of the determined contact times, the amount of MB dye from the liquid part was determined spectrophotometrically (Fig. 2f). From the obtained findings, it was determined that when $75 \mu \mathrm{L} \mathrm{H}_{2} \mathrm{O}_{2}$ was added to the reaction medium, 87.4\%, and when $600 \mu \mathrm{L} \mathrm{H}_{2} \mathrm{O}_{2}$ was added, $95.15 \mathrm{MB}$ was removed from the water. At the end of the research, it was determined that the optimum $\mathrm{H}_{2} \mathrm{O}_{2}$ concentration was reached by using $20 \mathrm{mg} / \mathrm{L}\left(600 \mu \mathrm{L}\right.$ of $\left.30 \% \mathrm{H}_{2} \mathrm{O}_{2}\right)$. Abhilasha et al. showed in their research that they use $130 \mu \mathrm{L}(30 \%) \mathrm{H}_{2} \mathrm{O}_{2}$ (Abhilasha 2016). Ayodamope studied the amount of $\mathrm{H}_{2} \mathrm{O}_{2}$ in the range of $50-200 \mathrm{mg} / \mathrm{L}$ in their study and found that the most suitable concentration is $100 \mathrm{mg} / \mathrm{L}$ (Ayodamope 2015).

\section{Characterization of nanobiocatalyst before and after dye removal}

Chitosan was reacted with powdered sunflower (S), and structural changes from the FT-IR data of S and the resulting CSN were clearly seen (Figs. 3 and 4a). It was obtained by the interaction of Fenton catalyst CSN and MB dye. FT-IR image (Fig. 4b) Similar to the work of Divakaran and his group, it was understood that nano-iron was in the structure of the biocatalyst by comparing with specific peaks in FT-IR (Divakaran 2011).

According to the FT-IR analysis results, the chemical structure of CSNs synthesized from sunflower, their binding, and the change of CSN structure after removal of MB dye by Fenton reaction were determined (Figs. $4 a$ and b). FTIR spectrum of CSNs and iron NPs showed major absorption bands at 3303.7, 2944.9, 1004.8, $881 \mathrm{~cm}^{-1}$, respectively. The dense and wide absorption band observed at $3303 \mathrm{~cm}^{-1}$ was due to the stress vibration of $\mathrm{O}-\mathrm{H}$. The amount of water present in CSNs is indicative of their hydrophilic structures, consistent with the $-\mathrm{O}-\mathrm{H}$ binding observed in broad spectra of CSNs between $3014 \mathrm{~cm}^{-1}$ and $3589 \mathrm{~cm}^{-1}$. It was determined that the $2902 \mathrm{~cm}^{-1}$ in Fig. $4 \mathrm{~b}$ corresponds to the stress vibration in the MB paint in CSNs and is caused by the CSN structure, and its width increases at the peak in 3303.7. The vibration band at $1614 \mathrm{~cm}^{-1}$ was determined to be caused

Fig. 3 Fenton process with CSN

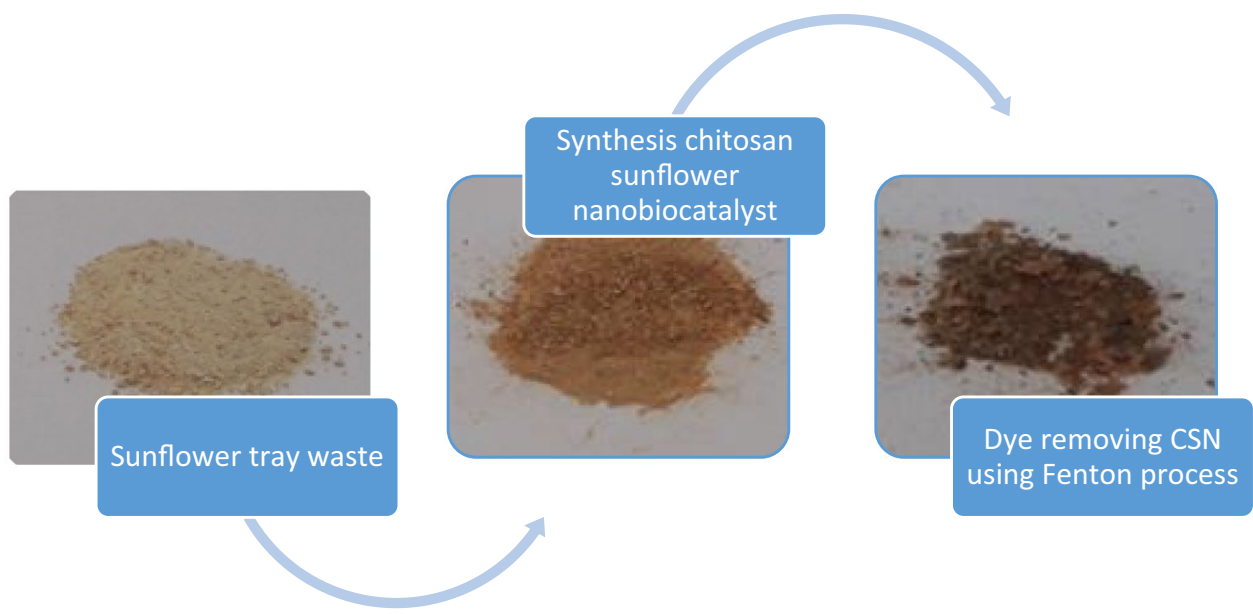

Fig. 4 a Shows FT-IR of sunflower (S) and CSN. b FT-IR obtained by interaction of CS dye Fenton catalyst and MB dye
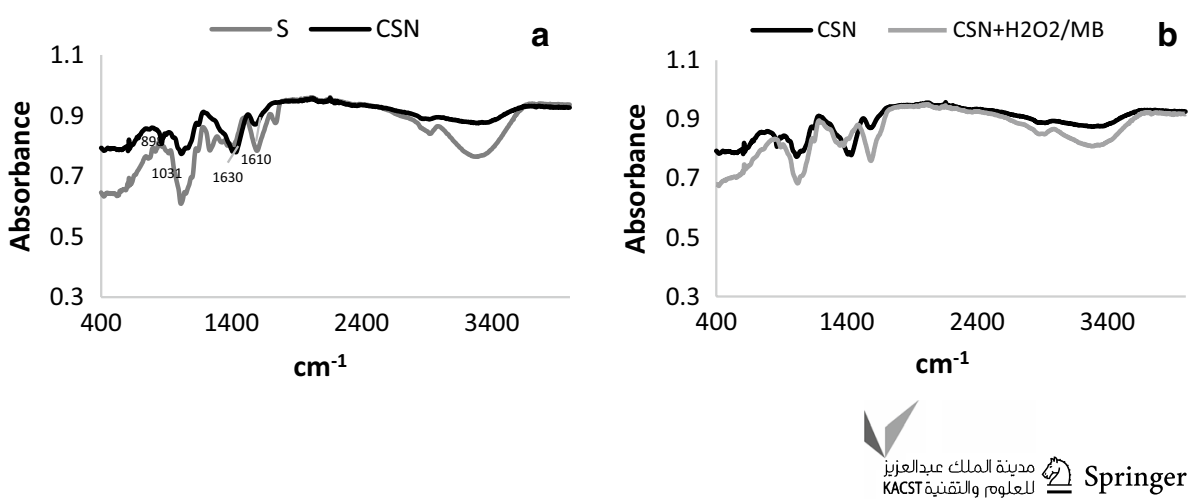
by the vibration of the MB/CSN structure after MB was attached. The bands with $1378 \mathrm{~cm}^{-1}$ centers belong to the $\mathrm{N}-\mathrm{O}$ stretch of the aliphatic nitro compound. The bands at $1378 \mathrm{~cm}^{-1}$ shifted to $1434 \mathrm{~cm}^{-1}$ after the Fenton reaction. The $1614 \mathrm{~cm}^{-1}$ absorption bands in the CSN are related to the $\mathrm{C}-\mathrm{O}$ stretch. Peak was observed at $1006.7 \mathrm{~cm}^{-1}$ of the $\mathrm{C}-\mathrm{OH}$ stretch vibration within the cellulosic structure.

XRD images of S and CSN were examined before the reaction (Fig. 5a). Because of the reaction, changes in the structure were shown in XRD images obtained by the interaction of CSN Fenton catalyst and MB dye (Fig. 5b). It was understood that the XRD data obtained were in harmony with the XRD images obtained by the study of Xin et al. In addition, because of the reaction understood from XRD, it is in the form that iron is present in the structure.

XRD study showed the presence of characteristic diffraction peaks of CSNs at $20.6^{\circ}, 16.9^{\circ}, 32.2^{\circ}, 33.6^{\circ}, 38.0^{\circ}, 44.9^{\circ}$ (Fig. 5a, and b). The XRD pattern of CSNs showed diffraction peaks at $2 \theta$ values of $33.6^{\circ}, 38.0^{\circ}, 44.9^{\circ}$, which are typical fingerprints of CSNs. These peaks belong to structures 104,110 , and 113, respectively, and are consistent with the literature.

SEM analysis of CSN synthesized using $\mathrm{S}$ and $\mathrm{S}$ is shown in Fig. 6a. SEM image is obtained by the interaction of Fenton catalyst CSN and MB dye (Fig. 6b). In SEM image, it can be observed that the paint is covered on the surface.
CSN structure and morphology of CSN after MB removal by Fenton reaction were examined by SEM analysis. From Fig. 6, SEM micrographs were determined that the CSN structure had a large difference in roughness and surface morphology. SEM analysis for CSN (6a) showed a nonsmooth and non-homogeneous surface, while the $6 \mathrm{~b}$ the structure showed that after MB dye removal, the rough structure became homogeneous.

The results of TEM analysis of S and CSN obtained in the synthesis result used in Fenton reagent synthesis Fig. 7a. It is also shown. The TEM image (Fig. 6b) obtained by the interaction of Fenton catalyst CSN and MB dye is also shown. When the TEM images were examined, it was understood that the nano-iron and $\mathrm{MB}$ on the surface were on the nanobiocatalyst.

\section{Conclusions}

In our research, iron nanoparticles synthesized using the green nano-synthesis method were used for the removal of MB in waters by Fenton reaction. For this purpose, iron nanoparticles were coated and immobilized on the synthesized CS. In this way, it can be prevented that the Fenton reagent used can easily be separated from the environment because of the reaction and causing extra pollution for the environment. For this purpose, the maximum absorbance
Fig. 5 a Shows the XRD data of $S$ and CSN. $\mathbf{b}$ XRD image obtained by the interaction of Fenton catalyst CSN and MB dye
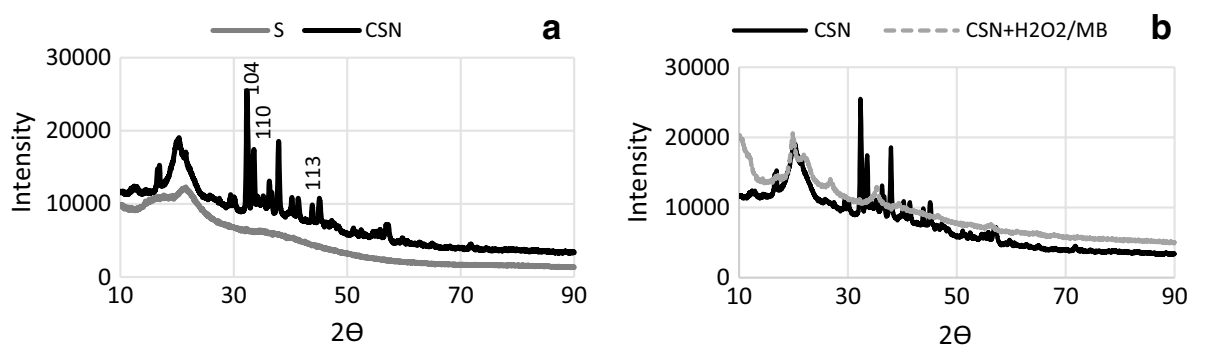
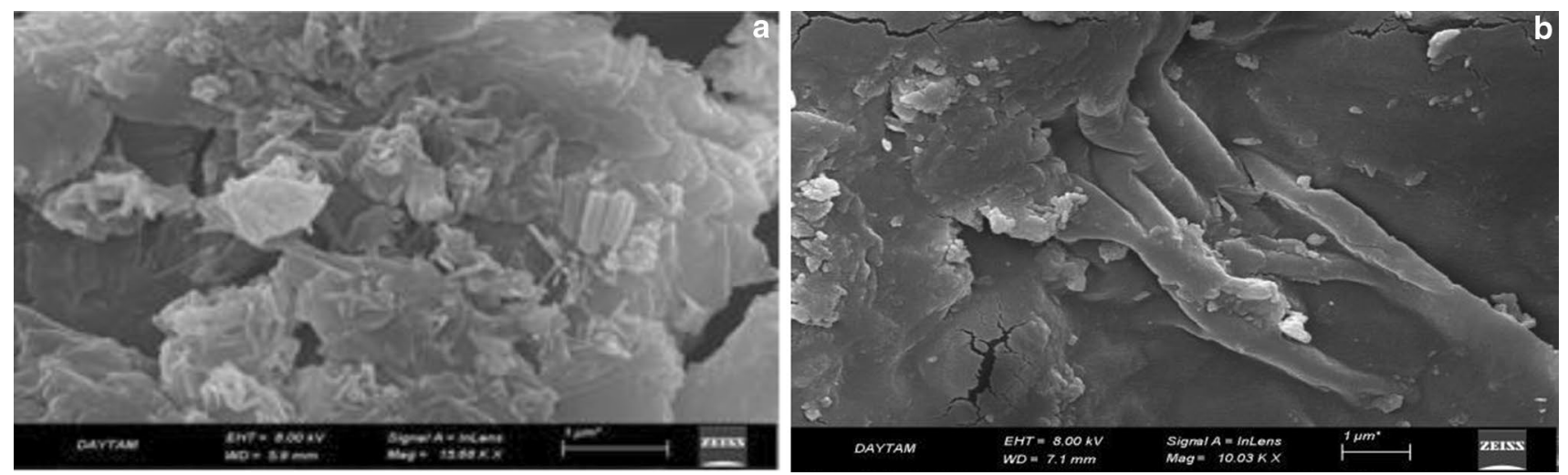

Fig. 6 a Shows the SEM analysis of CSN. b SEM image obtained by interaction of CS dye Fenton catalyst and MB dye 

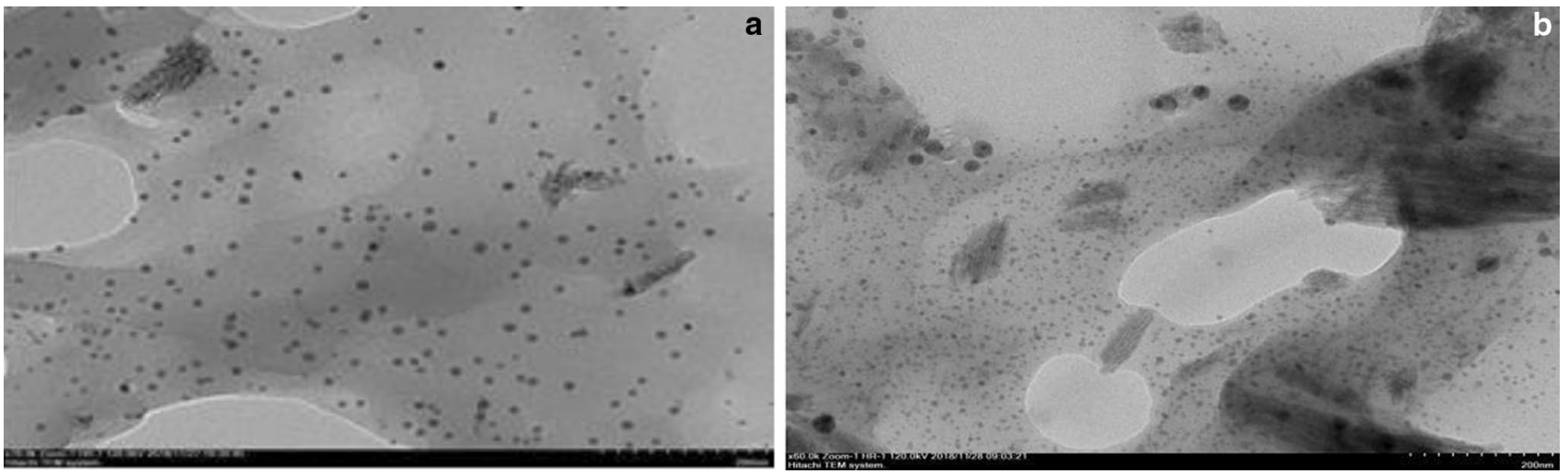

Fig. 7 a shows the TEM analysis of S and CSN b TEM image obtained by the interaction of fenton catalyst CSN and MB dye

wavelength of MB dye, which is $660 \mathrm{~nm}$, was followed by using a spectrophotometer, which is an easy tracking method. It was found that dye removal occurred at $\mathrm{pH} 6$, which is a $\mathrm{pH}$ close to neutral $\mathrm{pH}$ at $270 \mathrm{~min}$. It was also determined that $2.5 \mathrm{mg} / \mathrm{ml}$ nano-biocatalyst was used for $25 \mathrm{mg} / \mathrm{L}$ dye. In experiments about how the temperature of the reaction changes the dye removal, it was determined that $50 \%$ of the dye was removed from the reaction medium even at $40{ }^{\circ} \mathrm{C}$, while the maximum absorbance was $60{ }^{\circ} \mathrm{C}$. In addition, a successful reaction nanobiocatalyst has been developed in which $98 \%$ of the dye is removed by Fenton reaction under optimum conditions using very little peroxide. From SEM, TEM, XRD, and FT-IR results, the change in the surface of the biocatalyst can be clearly observed. Because of your experiments, it was observed that MB was removed from the water at very high rates such as $98 \%$ under optimum conditions. In addition, the Fenton reaction is an easy walking reaction in acidic environments and its nanobiocatalyst's activity at higher $\mathrm{pHs}$ is one of the areas where it is advantageous compared to other methods. For these reasons, we think that the newly produced CSN, which is abundant in nature, using biocompatible, biodegradable, and non-toxic materials, can be used as a Fenton reaction catalyst, with a lot of functionality to remove MB (or different dyes) with high success in wastewater.

Funding The article was prepared without any funds.

\section{Compliance with ethical standards}

Conflict of interest The authors report no conflicts of interest.

Ethical approval The authors participated in the preparation of the article. All the authors have read and approved the article.

Open Access This article is licensed under a Creative Commons Attribution 4.0 International License, which permits use, sharing, adaptation, distribution and reproduction in any medium or format, as long as you give appropriate credit to the original author(s) and the source, provide a link to the Creative Commons licence, and indicate if changes were made. The images or other third party material in this article are included in the article's Creative Commons licence, unless indicated otherwise in a credit line to the material. If material is not included in the article's Creative Commons licence and your intended use is not permitted by statutory regulation or exceeds the permitted use, you will need to obtain permission directly from the copyright holder. To view a copy of this licence, visit http://creativecommons .org/licenses/by/4.0/.

\section{References}

Abhilasha J, Ashma A, Marazban KA (2016) Greener approach for the degradation of dye methylene blue by organic additive catalysed photo-Fenton process. J Chil Chem Soc 61(3):3043-3048

Ai Z, Lu L, Li J, Zhang L, Qiu J, Wu M (2007) Fe@Fe2O3 coreshell nanowires as iron reagent. 1. efficient degradation of rhodamine B by a novel sono-Fenton process. J Phys Chem C 111(11):4087-4093

Ameta A, Ameta R, Ahuja M (2013) Photocatalytic degradation of methylene blue over ferric tungstate. Sci Revs Chem Commun 3:172-180

Ayodamope EO (2015) Oxidative degradation of methylene blue using Fenton reagent. Int J Sci Eng Res 6(11):984-995

Divakaran SA, Sreekanth KM, Rao KV, Nair CKK (2011) D-Aminoacid oxidase- $\mathrm{Fe}_{2} \mathrm{O}_{3}$ nanoparticle complex mediated antitumor activity in swis albino mice. J Cancer Ther 2(5):666-674

Ghosh D, Krishna GB (2002) Adsorption of methylene blue on kaolinite. Appl Clay Sci 20(6):295-300

Gungor AA, Nadaroglu H, Celebi N (2014) Fenton process for basic red 9 degradation: immobilized apolaccase on a nanomagnetite system. Environ Exp Biol 12:121-129

Gungor AA, Çelebi N, Nadaroğlu H (2015) Removal of basic red 9 in wastewater using green Fenton reaction. Fresenius Environ Bull 24(5):1947-1957

Gungor AA, Nadaroglu H, Kalkan E, Celebi N (2016) Fenton process-driven decolorization of allura red $\mathrm{AC}$ in wastewater using apolaccase-modified or native nanomagnetite immobilized on silica fume. Desalin Water Treat 57:15889-15899 
Gupta VK, Suhas AI, Saini VK (2004) Removal of rhodamine B, fast green and methylene blue from wastewater using red mud, an aluminum industry waste. Ind Eng Chem Res 43:1740-1747

Horstman Fenton HJ, Jackson HJ (1899) The oxidation of polyhydric alcohols in presence of iron. J Chem Soc Trans 75:1-11

Houas AH, Lachheb M, Ksibi E, Elaloui GC (2001) Photocatalytic degradation pathway of methylene blue in water. Applid Catal B: Environ 31:145-157

Karadag D, Tok S, Akgul E, Ulucan K, Evden H (2006) Combining adsorption and coagulation for the treatment of azo and anthraquinone dyes from aqueous solution. Ind Eng Chem Res 45:3969-3973

Karaduman I, Güngör AA, Nadaroğlu H, Altundaş A, Acar S (2017) Green synthesis of $\gamma-\mathrm{Fe}_{2} \mathrm{O}_{3}$ nanoparticles for methane gas sensing. J Mater Sci: Mater Electron 28:16096-16105

Kaya Y (2016) Sunflower, breeding oilseed crops for sustainable production. 55-88.

Loloei M, Rezaee A (2016) Decolorization of methylene blue by the electro-Fenton process using stainless steel mesh electrodes. Int J Env Health Eng 5:27

Maldonado MCC, Duconge J, Morant C, Márquez F (2017) Investigating the water sealing capability of polymer concrete. Am J Eng Appl Sci 10(2):373-381.

Marin JM, Montoya J, Monsalve E, Granda CF, Rios LA (2007) Degradation of methyl orange by a new solar photoreactor. Sci Et Tech 13:435-440
Nadaroglu H, Gungor AA, Celebi N (2015) Removal of basic red 9 (BR9) in aqueous solution by using silica with nano-magnetite by enzymatic with Fenton process. Int J Environ Res 9(3):991-1000

Nadaroğlu H, Lesani A, Soleimani SS, Babagil A, Güngör AA (2018) Efficient solar photocatalyst based on $\mathrm{TiO}_{2} /$ corn silk NPs composite for removal of a textile azo-dye from aqueous solution. IIOAB J 9(4):20-27

Nalcı ÖB, Nadaroğlu H, Pour A, Güngör AA, Haliloglu K (2018) Effects of $\mathrm{ZnO}, \mathrm{CuO}$ and $\gamma$-Fe3O4 nanoparticles on mature embryo culture of wheat (Triticum aestivum L.). Plant Cell, Tissue Organ C (PCTOC) 136:0167-6857

Turgut E (2019) Production of new biosorbent materials based on chitosan, nanoparticle and sunflower plants and investigation of their usability for dye removal, Master Thesis, Atatürk University Nanoscience and Nano Engineering, Erzurum.

Uddin T, Islam A, Mahmud S, Rukanuzzaman MB (2009) Adsorptive removal of methylene blue by tea waste. J Hazard Mater 164(1):53-60

Publisher's Note Springer Nature remains neutral with regard to jurisdictional claims in published maps and institutional affiliations. 